\title{
Effect of prepaid and promised financial incentive on follow-up survey response in cigarette smokers: a randomized controlled trial
}

Yee Tak Derek Cheung ${ }^{1}$, Xue Weng ${ }^{1}$, Man Ping Wang ${ }^{1 *}$ (D), Sai Yin $\mathrm{Ho}^{2}$, Antonio Cho Shing Kwong ${ }^{3}$, Vienna Wai Yin Lai ${ }^{3}$ and Tai Hing Lam²

\begin{abstract}
Background: Monetary incentive is often used to increase response rate in smokers' survey, but such effect of prepaid and promised incentives in a follow-up survey is unknown. We compared the effect of different incentive schemes on the consent and retention rates in a follow-up survey of adult cigarette smokers.

Methods: This was a randomized controlled trial (RCT) in Hong Kong, China. Smokers who completed a non-incentivized baseline telephone smoking survey were invited to a 3-month follow-up, with randomization into (1) the control group (no incentive), (2) a promised HK\$100 (US\$12.8) incentive upon completion, (3) a promised HK\$200 (US\$25.6) incentive upon completion, or (4) a prepaid HK\$100 incentive plus another promised HK\$100 incentive ("mixed incentive"). Crude risk ratios from log-binomial regression models were used to assess if the 3 incentive schemes predicted higher rates of consent at baseline or retention at 3-month than no incentive.

Results: In total, 1246 smokers were enrolled. The overall consent and retention rates were 37.1 and 23.0\%, respectively. Both rates generally increased with the incentive amount and offer of prepaid incentive. The mixed incentive scheme marginally increased the retention rate versus no incentive (26.8\% vs $20.3 \%$; risk ratio (RR) $=1.32 ; 95 \% \mathrm{Cl}: 1.00-1.76 ; P=$ $0.053)$, but not the consent rate $(\mathrm{RR}=1.13 ; 95 \% \mathrm{Cl}: 0.93-1.38 ; P=0.22)$. Among the consented participants, approximately $50 \%$ in the mixed incentive group received the mailed prepaid incentive, who achieved a higher retention rate than the group without incentives (82.8\% vs 56.1\%; $\mathrm{RR}=1.48 ; 95 \% \mathrm{Cl}: 1.21-1.80 ; P<0.01$ ).

Conclusion: The mixed incentive scheme combining the prepaid and promised incentive was effective to increase the follow-up retention rate by $48 \%$. We recommend this mixed incentive scheme to increase the follow-up retention rate. More efficient methods of delivering the incentive are needed to maximize its effects.
\end{abstract}

Trial registration: U.S. Clinical Trials registry (clinicaltrials.gov, retrospectively registered, reference number: NCT03297866). Keywords: Incentive, Follow-up, Randomized controlled trial, Smoker

\footnotetext{
* Correspondence: mpwang@hku.hk

${ }^{1}$ School of Nursing, The University of Hong Kong, Hong Kong, China

Full list of author information is available at the end of the article
}

(c) The Author(s). 2019 Open Access This article is distributed under the terms of the Creative Commons Attribution 4.0 International License (http://creativecommons.org/licenses/by/4.0/), which permits unrestricted use, distribution, and reproduction in any medium, provided you give appropriate credit to the original author(s) and the source, provide a link to the Creative Commons license, and indicate if changes were made. The Creative Commons Public Domain Dedication waiver (http://creativecommons.org/publicdomain/zero/1.0/) applies to the data made available in this article, unless otherwise stated. 


\section{Background}

Tobacco control polices require representative and longitudinal cohort samples for rigorous evaluation. Although telephone surveys remain an effective approach for population-based surveillance, conducting a representative telephone survey has become more difficult in recent years owing to household landlines being increasingly replaced by mobile phones, the wide use of answering devices and voicemail, and frequent telemarketing in an over-surveyed society like Hong Kong [1-5]. Recent observational studies face increasing challenges from nonresponses [6-8], which may introduce nonresponse bias $[9,10]$ in estimating public opinions for policy-making.

Loss to follow-up in tobacco control cohort surveys is an ongoing challenge. Non-respondents tend to have lower socioeconomic status [11] and have no intention to quit smoking [12]. Hence, monetary incentives are often promised for completing follow-up surveys, and larger incentives have yielded higher response rates [13, 14]. However, large incentives may not be practical due to budget constraints.

Prepaid incentives appear to be a feasible alternative to promised incentives for mail [15, 16], face-to-face [17], and telephone surveys [18]. The Social Exchange Theory posits that offering prepaid incentive fosters a trusting relationship with the participants, who would feel obliged to reciprocate by responding to the follow-up survey $[19,20]$. In addition, the behavioral theory on present-biased preferences suggests that current potential rewards and costs have a larger impact than those in the future [21]. Therefore, incentive schemes with prepaid and earlier rewards should be more attractive than other schemes with the same amount but delayed rewards [22, 23]. To the best of our knowledge, no study has rigorously tested the effect of prepaid incentive on smokers' follow-up retention, and little is known about the effect of payment amount or timing on follow-up survey retention.

This was the first randomized controlled trial (RCT) aimed to assess the effect of payment amount (HK\$100 (US\$12.8) or HK\$200 (US\$25.6)) and payment timing (prepaid or promised) on smokers' consent and completion of a follow-up survey at 3 months. We hypothesized that (1) the effects of incentive increase with the amount offered and that (2) a combination of prepaid and promised incentive yields better response than no incentive.

\section{Methods}

\section{Trial design and subjects}

This was a parallel 4-armed, individual RCT with equal allocation ratio, which was nested within the Tobacco Control Policy-related Survey (TCPS) 2017. The TCPS 2017 is a representative, cross-sectional, telephone opinion survey (baseline survey) on tobacco control in Hong Kong [24], where smoking prevalence has declined from $23.3 \%$ in 1982 to $10.0 \%$ in 2017 [25]. Approximately 25\% of smokers in Hong Kong are hardcore smokers [26, 27]. The baseline survey adopted a two-stage random sampling strategy by initially randomly drawing landline telephone numbers from residential telephone directories and then selecting the adult (aged 18 years or above) family member who had the next birthday soonest. The survey was administered by a trained interview survey agent. Details of the survey have been reported elsewhere $[28,29]$. Respondents who self-reported current use of cigarettes were eligible for the RCT. Before each survey, they gave verbal informed consent with the knowledge that the survey data were for quantitative analysis and that the interview would be audio-recorded. The baseline survey of the RCT was conducted from late June to mid-October 2017. All follow-up interviews were completed by late January 2018. This study has been approved by the Institutional Review Board of the University of Hong Kong/Hospital Authority Hong Kong West Cluster (IRB reference number: UW 17-084) and registered in the U.S. Clinical Trials registry (reference number: NCT03297866).

\section{Survey incentives}

We set the basic incentive to HK\$100 (US\$12.8), which was equivalent to $3 \mathrm{~h}$ of minimum wage in 2017 (HK\$34.5 (US\$4.4)) and was greater than those in previous trials of prepaid incentive targeting the general population [30-32].

After completing the baseline survey, all eligible participants were invited for a similar 3-month follow-up survey with a question: "The School of Nursing and School of Public Health of the University of Hong Kong would like to contact you later to collect more opinion on tobacco health warnings and other tobacco control policies. Would you like to participate? If you agree, please tell me your contact number and the research staff will contact you soon." They were randomly allocated using the survey system run by the survey agency (Public Opinion Programme of the University of Hong Kong) into one of the 4 groups of incentive schemes: (1) no incentive, (2) a promised HK\$100 incentive (i.e., a HK\$100 supermarket voucher after completing the follow-up survey), (3) a promised HK\$200 incentive (i.e., a HK\$200 supermarket voucher after completing the follow-up survey), and (4) a mixed incentive (i.e., a HK\$100 supermarket voucher for agreeing to participate in the follow-up survey and another HK\$100 supermarket voucher after completing the follow-up survey). Respondents allocated to receive incentives (groups 2-4) were informed of the respective incentives to encourage their participation.

All consented participants were asked to provide only the telephone number for re-contact but not also the postal address because we considered that collecting too many personal details may deter their consent to the follow-up. Participants in the mixed incentive group who consented 
to the follow-up were re-contacted twice at most within 2 weeks to collect the mailing address for the pre-survey incentive. Those who could not be reached were deemed to have not successfully received the incentive, but they were still contacted for the follow-up survey and were given $\mathrm{HK} \$ 200$ incentive for completing it. All follow-up telephone interviews were conducted by experienced interviewers blinded to the group allocation. Each respondent was called up to 7 times at different time slots within 1 month. All incentives were sent using registered mails.

\section{Randomization, allocation concealment and blinding}

Randomization was conducted using a computerized interview system of the survey agent after the respondents confirmed their smoking status and gave informed consent, hence the group allocation was concealed to both interviewers and participants before randomization. Both interviewers and the participants were not blinded about their respective intervention (i.e. incentive scheme), but the 3month follow-up interviewers were blinded.

\section{Outcomes}

The primary outcomes were (1) the consent rate (i.e., the proportion of participants who consented to the 3month follow-up at baseline) and the (2) retention rate (i.e., the proportion of participants who completed the 3-month follow-up). Adopting the intention-to-treat principle, both outcomes were assessed using all eligible and consented participants as the denominator. To distinguish the effect between receiving and not receiving the prepaid incentive, we added the retention rate among the consented participants as an additional outcome, which was not stated in the original protocol.

\section{Statistical analyses}

The sample size was constrained by the limited baseline survey period and limited funding; thus, the optimal sample size $(n=1336$ for a risk ratio of 1.33 comparing 2 groups, power $=80 \%$, and alpha $=0.05$ ) in examining the effectiveness of prepaid and promised incentives was not achieved. We used Chi-square test to assess if the sociodemographic characteristics were balanced among the trial groups. We reported risk ratios from log-binomial regression model instead of odds ratios from logistic regression, because the outcome events in this study were common (proportion of $20 \%$ or more). Crude risk ratios from logbinomial regression models were used to assess if the three incentive schemes yielded higher rates of consent or retention than no incentive. Predictors with $P$-values below 0.1 in univariate analysis were included in multivariate logbinomial regression models to generate adjusted risk ratios. Interactions between the incentive schemes and other significant predictors were then included in the models. All data analyses were conducted using IBM SPSS Statistics, version 23 . A two-sided $P$-value less than 0.05 was considered statistically significant.

\section{Results}

A total of 1246 participants who reported currently smoking were invited at baseline, and were included in the final analysis. The number of subjects in the 4 trial groups were 316, 326, 283 and 321. Of all participants, 84\% were men and the participant mean age was 55.1 years. Most participants attained secondary education level, were either married or cohabitating, employed, had children, were daily cigarette smokers, and born in Hong Kong (Table 1). Approximately $25 \%$ smoked their first cigarette within $5 \mathrm{~min}$ after waking, and approximately $50 \%$ reported no intention to quit smoking. No significant difference in baseline sociodemographic and smoking characteristics was noted among the 4 arms (all $P$-values $>0.05$ ).

Overall, 462 (37.1\%) participants consented to the follow-up and provided their mobile or landline telephone number for further contact (Table 2). Of them, 287 (23.0\%) completed the follow-up survey. The mixed incentive group had the highest consent rate $(40.8 \%)$, followed by the promised $\$ 200$ incentive group (37.8\%), although they were not significantly different from the no incentive or control group (36.1\%). The retention rates increased with the amount of incentives (no incentive, 20.3\%; \$100 incentive, 21.2\%; \$200 incentive, 24.0\%) and was highest for the mixed incentive group (26.8\%). Compared with the control group, the mixed incentive group showed a higher retention rate $(\mathrm{RR}=1.32$, 95\% CI: $1.00-1.76 ; P=0.053)$, with marginal significance.

Of the 131 participants who consented to the follow-up in the mixed incentive group, 64 (48.9\%) received the prepaid incentive. The other 67 participants did not receive the prepaid incentive, including 50 (74.6\%) who could not be contacted by the subsequent follow-up interviewer to provide a mailing address, 14 (20.9\%) who refused to provide their mailing address but agreed to the later follow-up, and $3(3.4 \%)$ who refused the later follow-up. The retention rate was higher in those who received the prepaid incentive $(82.8 \%)$ than in those who did not (49.3\%).

Among the participants who consented to the followup, the retention rate was significantly higher in those who received the prepaid incentive in the mixed incentive group $(82.8 \%)$ than that in the control group (56.1\%) (adjusted RR (ARR) $=1.48,95 \%$ CI: $1.21-1.80$; $P<0.01)$. Meanwhile, the participants in the mixed incentive group who did not receive the prepaid incentive had a lower retention rate than the control group (49.3\% vs 56.1\%); however, the ARR was non-significant (ARR = 0.88, 95\% CI: 0.66-1.18; $P=0.38$ ) (Table 2).

In the multivariate models, higher education level, being born in Hong Kong (versus Mainland China and other places), and having an intention to quit were associated 
Table 1 Sample characteristics according to incentive schemes at baseline $(n=1246)$

\begin{tabular}{|c|c|c|c|c|c|}
\hline & $\begin{array}{l}\text { No incentive } \\
(n=316)\end{array}$ & $\begin{array}{l}\text { Promised HK\$100 } \\
\text { incentive }(n=326)\end{array}$ & $\begin{array}{l}\text { Promised HK\$200 } \\
\text { incentive }(n=283)\end{array}$ & $\begin{array}{l}\text { Mixed incentive } \\
(n=321)\end{array}$ & $P$-value \\
\hline Sex & & & & & 0.82 \\
\hline Male & $264(83.8)$ & $277(85.0)$ & $243(85.9)$ & $268(83.5)$ & \\
\hline Female & $51(16.2)$ & $49(15.0)$ & $40(14.1)$ & $53(16.5)$ & \\
\hline Age group (years) & & & & & 0.49 \\
\hline$<=39$ & $59(18.9)$ & $51(15.6)$ & $51(18.0)$ & $64(19.9)$ & \\
\hline $40-59$ & $132(42.0)$ & $134(41.1)$ & $102(36.0)$ & $129(40.2)$ & \\
\hline$>=60$ & $123(39.2)$ & $141(43.3)$ & $130(45.9)$ & $128(39.9)$ & \\
\hline \multicolumn{6}{|l|}{ Education level } \\
\hline Primary or below & $63(20.2)$ & $71(21.8)$ & $69(24.4)$ & 69 (21.6) & 0.80 \\
\hline Secondary & $189(60.6)$ & $188(57.7)$ & $159(56.2)$ & $178(55.8)$ & \\
\hline Tertiary & $60(19.2)$ & $67(20.6)$ & $55(19.4)$ & $72(22.6)$ & \\
\hline Marital status & & & & & 0.57 \\
\hline Single & $63(20.2)$ & $53(16.3)$ & $50(17.9)$ & $66(20.8)$ & \\
\hline Married / Cohabit & $222(71.2)$ & $233(71.5)$ & $198(70.7)$ & $215(67.8)$ & \\
\hline Divorced/Separated/Widowed & $27(8.7)$ & $40(12.3)$ & $32(11.4)$ & $36(11.4)$ & \\
\hline Employment status & & & & & 0.31 \\
\hline Employed & $182(58.1)$ & $180(55.4)$ & $139(50.4)$ & $186(58.3)$ & \\
\hline Retired & $100(31.9)$ & $119(36.6)$ & $105(38.0)$ & $100(31.4)$ & \\
\hline Others & $31(9.9)$ & $26(8.0)$ & $32(11.6)$ & $33(10.3)$ & \\
\hline $\begin{array}{l}\text { Monthly household income } \\
\text { (HKD; US\$1 = HK\$7.8) }\end{array}$ & & & & & 0.29 \\
\hline Below $\$ 10,000$ & $65(23.4)$ & $57(19.8)$ & $54(21.9)$ & $52(18.7)$ & \\
\hline$\$ 10,000-\$ 29,999$ & $95(34.2)$ & $99(34.4)$ & $101(40.9)$ & $96(34.5)$ & \\
\hline$\$ 30,000$ or above & $118(42.4)$ & $132(45.8)$ & $92(37.2)$ & $130(46.8)$ & \\
\hline Had children & $219(71.3)$ & $246(76.4)$ & $209(75.5)$ & $220(69.8)$ & 0.19 \\
\hline Had children under 16 years & $46(15.0)$ & $65(20.3)$ & $55(20.0)$ & $54(17.1)$ & 0.28 \\
\hline Place of origin & & & & & 0.57 \\
\hline Hong Kong & $181(58.4)$ & $188(58.6)$ & $164(58.8)$ & $200(63.5)$ & \\
\hline China Mainland & $118(38.1)$ & $127(39.6)$ & $108(38.7)$ & $105(33.3)$ & \\
\hline Others & $11(3.5)$ & $6(1.9)$ & $7(2.5)$ & $10(3.2)$ & \\
\hline Perceived health status & & & & & 1.00 \\
\hline Extremely /very good & $85(27.6)$ & 99 (30.8) & 79 (28.4) & $92(29.1)$ & \\
\hline Good & $83(26.9)$ & $80(24.9)$ & 79 (28.4) & $82(25.9)$ & \\
\hline Fair & $115(37.3)$ & $117(36.4)$ & $97(34.9)$ & $118(37.3)$ & \\
\hline Bad & $25(8.1)$ & $25(7.8)$ & $23(8.3)$ & $24(7.6)$ & \\
\hline Time to first smoking after waking & & & & & 0.57 \\
\hline$<5 \min$ & $72(26.2)$ & $76(25.5)$ & $71(28.1)$ & $75(25.8)$ & \\
\hline $6-30 \min$ & $69(25.1)$ & $84(28.2)$ & $71(28.1)$ & $91(31.3)$ & \\
\hline $31-60 \min$ & $37(13.5)$ & $29(9.7)$ & $31(12.3)$ & $40(13.7)$ & \\
\hline After 60 min & $97(35.3)$ & 109 (36.6) & $80(31.6)$ & $85(29.2)$ & \\
\hline Daily cigarette users & & & & & 0.11 \\
\hline Yes & $256(82.1)$ & $250(77.2)$ & $240(84.8)$ & $261(81.6)$ & \\
\hline No & $56(17.9)$ & $74(22.8)$ & $43(15.2)$ & $59(18.4)$ & \\
\hline
\end{tabular}

Daily cigarette consumption (sticks) 
Table 1 Sample characteristics according to incentive schemes at baseline $(n=1246)$ (Continued)

\begin{tabular}{|c|c|c|c|c|c|}
\hline & $\begin{array}{l}\text { No incentive } \\
(n=316)\end{array}$ & $\begin{array}{l}\text { Promised HK\$100 } \\
\text { incentive }(n=326)\end{array}$ & $\begin{array}{l}\text { Promised HK\$200 } \\
\text { incentive }(n=283)\end{array}$ & $\begin{array}{l}\text { Mixed incentive } \\
(n=321)\end{array}$ & $P$-value \\
\hline $1-10$ & $149(52.5)$ & $150(53.8)$ & $111(43.4)$ & $145(49.8)$ & \\
\hline $11-20$ & $114(40.1)$ & $115(41.2)$ & $126(49.2)$ & $118(40.5)$ & \\
\hline $21-30$ & $13(4.6)$ & $11(3.9)$ & $13(5.1)$ & $16(5.5)$ & \\
\hline$>30$ & $8(2.8)$ & $3(1.1)$ & $6(2.3)$ & $12(4.1)$ & \\
\hline Intention to quit & & & & & 0.93 \\
\hline No intention & 169 (54.9) & $172(54.6)$ & $153(55.4)$ & $177(56.5)$ & \\
\hline Within 30 days & $49(15.9)$ & $54(17.1)$ & $41(14.9)$ & $42(13.4)$ & \\
\hline After 30 days & $90(29.2)$ & $89(28.3)$ & $82(29.7)$ & $94(30.0)$ & \\
\hline Ever used Ecigs or HTP & & & & & 0.24 \\
\hline Yes & $72(22.8)$ & $72(22.1)$ & $50(17.7)$ & $78(24.3)$ & \\
\hline No & $244(77.2)$ & 254 (77.9) & $233(82.3)$ & $243(75.7)$ & \\
\hline
\end{tabular}

Mixed incentive: Prepaid HK\$100 incentive and promised HK\$100 incentive; Ecigs or HTP: E-cigaretes or heated tobacco products; Sample sizes varied because missing responses on some variables were not included in the percentage calculation. $P$-value calculated by Chi-squared test for categorical variables. All differences were due to chance (from randomization), and $P$ values are for reference only

with both higher consent and retention rates (Table 3). Female sex (versus male sex) and having children aged under 16 years were associated only with higher consent rate. All interaction terms were not significant.

\section{Discussion}

This RCT compared the effect of different incentive schemes on the consent and retention rates in a follow-up survey of adult cigarette smokers in Hong Kong, China. Our descriptive findings indicated that the consent and retention rates generally increased with the amount of incentive and were highest for the mixed incentive group. However, statistical significance was not achieved due to the small effect size and sample size. As no incentive was provided for the baseline survey, those who responded may tend to be altruistic rather than motivated by financial incentives. Such participants may therefore be less responsive to financial incentives for yet another survey.
In comparison, in the International Tobacco Control Policy Evaluation Project $[8,33]$, an incentivized baseline survey, yielded higher retention rates for follow-up surveys. Some of our participants might also be overburdened by the baseline survey (about $15 \mathrm{~min}$ ), which reduced their motivation to participate in a similar follow-up survey.

Our findings are consistent with those of trials that evaluated the effects of a prepaid incentive on survey participation [15, 30, 31, 34, 35]. Moreover, our results provided new evidence that the mixed incentive scheme increased the retention rate of baseline smokers for a follow-up survey compared with no incentive, although it was only marginally significant probably due to the small sample size. We have also provided empirical findings to support the aforementioned behavioral theories that rewards, particularly delivered early and unconditionally, can encourage participation or behavioral change [21,36]. Respondents' concerns about the credibility and confidentiality of the

Table 2 Consent and retention rates at 3-month follow-up according to incentive schemes ( $n=1246)$

\begin{tabular}{|c|c|c|c|c|c|c|}
\hline Incentive schemes & Consent rate $n(\%)$ & Risk ratio $(95 \% \mathrm{Cl})$ & $P$-value & Retention rate $n(\%)$ & Risk ratio $(95 \% \mathrm{Cl})$ & $P$-value \\
\hline All $(n=1246)$ & $462(37.1)$ & & & $287(23.0)$ & & \\
\hline No incentive & $114 / 316(36.1)$ & Ref & & $64 / 316(20.3)$ & Ref & \\
\hline Promised HK\$100 & $110 / 326(33.7)$ & $0.94(0.76,1.16)$ & 0.54 & $69 / 326(21.2)$ & $1.05(0.77,1.41)$ & 0.78 \\
\hline Promised HK\$200 & 107/283 (37.8) & $1.05(0.85,1.29)$ & 0.66 & 68/283 (24.0) & $1.19(0.88,1.60)$ & 0.27 \\
\hline Mixed incentive & 131/321 (40.8) & $1.13(0.93,1.38)$ & 0.22 & $86 / 321(26.8)$ & $1.32(1.00,1.76)$ & 0.053 \\
\hline Participants who consented $(n=462)$ & & & & $287(62.1)$ & & \\
\hline No incentive & - & - & - & $64 / 114(56.1)$ & Ref & \\
\hline Promised HK\$100 & - & - & - & $69 / 110(62.7)$ & $1.12(0.90,1.39)$ & 0.21 \\
\hline Promised HK\$200 & - & - & - & 68/107 (63.6) & $1.13(0.91,1.41)$ & 0.20 \\
\hline Mixed incentive not receiving prepaid & - & - & - & 33/67 (49.3) & $0.88(0.66,1.18)$ & 0.38 \\
\hline Mixed incentive receiving prepaid & - & - & - & $53 / 64(82.8)$ & $1.48(1.21,1.80)$ & $<0.01$ \\
\hline
\end{tabular}


Table 3 Predictors of consent at baseline and completion of the 3-month follow-up $(n=1246)$

\begin{tabular}{|c|c|c|c|c|}
\hline \multirow[b]{2}{*}{ Predictors } & \multicolumn{2}{|l|}{ Consented to follow-up } & \multicolumn{2}{|l|}{ Completed follow-up } \\
\hline & Adjusted risk ratio $(95 \% \mathrm{Cl})$ & $P$-value & Adjusted risk ratio $(95 \% \mathrm{Cl})$ & $P$-value \\
\hline Incentive schemes & & 0.18 & & 0.20 \\
\hline No incentive & Ref & & Ref & \\
\hline Promised HK\$100 & $0.92(0.75-1.13)$ & 0.92 & $1.07(0.79-1.45)$ & 0.65 \\
\hline Promised HK\$200 & $1.09(0.89-1.34)$ & 0.46 & $1.23(0.91-1.66)$ & 0.18 \\
\hline Mixed incentive & $1.14(0.94-1.38)$ & 0.20 & $1.33(1.00-1.77)$ & 0.05 \\
\hline \multicolumn{5}{|l|}{ Sex } \\
\hline Female & Ref & & - & - \\
\hline Male & $1.30(1.08-1.57)$ & $<0.01$ & - & - \\
\hline Age group (years) & & 0.49 & & \\
\hline $15-29$ & Ref & & & \\
\hline $30-39$ & $1.02(0.75,1.38)$ & 0.90 & - & - \\
\hline $40-49$ & $1.02(0.77,1.36)$ & 0.87 & - & - \\
\hline $50-59$ & $1.03(0.78,1.37)$ & 0.84 & - & - \\
\hline $60-65$ & $0.78(0.53,1.15)$ & 0.21 & - & - \\
\hline Above 65 & $1.05(0.71,1.55)$ & 0.81 & - & - \\
\hline Education level & & $<0.01$ & & 0.08 \\
\hline Primary or below & Ref & & Ref & \\
\hline Secondary & $1.45(1.14-1.84)$ & $<0.01$ & $1.32(0.98-1.79)$ & 0.07 \\
\hline Tertiary & $1.66(1.27-2.17)$ & $<0.01$ & $1.47(1.05-2.07)$ & 0.03 \\
\hline Employment status & & 0.14 & & \\
\hline Employed & Ref & & - & - \\
\hline Others & $1.17(0.93-1.49)$ & 0.17 & - & - \\
\hline Retired & $1.27(0.95-1.68)$ & 0.12 & - & - \\
\hline Had children under 16 & $1.28(1.07-1.54)$ & $<0.01$ & - & - \\
\hline Place of birth & & 0.01 & & $<0.01$ \\
\hline Hong Kong & Ref & & Ref & \\
\hline China Mainland & $0.80(0.67-0.95)$ & $<0.01$ & $0.74(0.58-0.93)$ & 0.01 \\
\hline Other places & $0.57(0.32-1.00)$ & 0.05 & $0.34(0.12-1.01)$ & 0.05 \\
\hline Intention to quit & & $<0.01$ & & 0.08 \\
\hline No intention & Ref & & Ref & \\
\hline Quit after 30 days & $1.37(1.13-1.65)$ & $<0.01$ & $1.13(0.84-1.52)$ & 0.43 \\
\hline Quit within 30 days & $1.31(1.11-1.54)$ & $<0.01$ & $1.30(1.04-1.62)$ & 0.02 \\
\hline \multicolumn{5}{|l|}{ Ever used Ecigs or HTP } \\
\hline No & Ref & & - & - \\
\hline Yes & $1.07(0.89-1.28)$ & 0.49 & - & - \\
\hline
\end{tabular}

HK\$100 = US\$12.8; Ecigs or HTP: E-cigarettes or heated tobacco products; Baseline predictors shown in the table had $p$-value below 0.1 in the univariate analysis. Other variables with $p$-value 0.1 or higher were not included in the multivariate models

research may negatively affect trust. The unconditional and prepaid incentive as an alternative to establish trust may have decreased the respondents' skepticism in our study, and this might have led to the greater 3-month retention.

The small effect size achieved by the mixed incentive scheme can be explained by the attrition rate in those who were told to receive the prepaid incentive. Only about half of the consented participants in the mixed incentive group were successfully contacted and given the prepaid \$100 incentive. We showed that missing the chance of collecting the mailing address to deliver the incentive immediately after obtaining the consent would result in attrition in the subsequent follow-up and non- 
compliance of the intervention. Moreover, the retention rate in those who received the prepaid incentive in the mixed incentive group was significantly higher than that in the control group. This result indicates the importance of successfully and efficiently delivering the prepaid incentive for sustaining the intervention compliance. Apart from the traditional methods to mail the incentive, new payment methods that can increase the payment efficiency such as electronic transactions are recommended.

We found that higher education level and being a local resident (i.e., Hong Kong Chinese versus China Mainland Chinese and ethnic minority) were independently associated with greater consent and retention rates, which were consistent with previous findings [37-39]. Our results provide additional evidence that lower or no intention to quit led to higher attrition of a follow-up survey. Findings from follow-up surveys such as those on the change of smoking behaviors and attitudes may not be representative of all smoking respondents and may inflate the public support towards tobacco control policies [40-42]. Population-based cohort studies need to adjust the results by weighting for these factors appropriately.

The strength of our study was that the participants were recruited and the main baseline survey was started during the first "cold call" without prior invitation or mailed prepaid incentive. Therefore, we showed the incentive effect independent of other recruitment incentive and strategies. Our method also collected more personal information from those who did not consent to the follow-up in the first cold call, which allowed us to examine the factors associated with consent.

We found that higher education level and being a local resident (i.e., Hong Kong Chinese versus China Mainland Chinese and ethnic minority) were independently associated with greater consent and retention rates, which were consistent with previous findings [37-39]. Our results provide additional evidence that lower or no intention to quit led to higher attrition of a follow-up survey. Findings from follow-up surveys such as those on the change of smoking behaviors and attitudes may not be representative of all smoking respondents and may inflate the public support towards tobacco control policies [40-42]. Population-based cohort studies need to adjust the results by weighting for these factors appropriately.

Nonetheless, this trial had several limitations. First, the sample size was constrained by the limited recruitment period and preset sample size of the baseline survey. Second, this trial only enrolled smokers, and the findings may not be generalized to the overall population. Third, the use of postal service to send the incentive is a delayed mode of remuneration. Instant incentives have been shown to markedly increase the response rates than promised incentives among nonresponding physicians [43]. Given the rapidly evolving communication and technological landscape, future trials may consider using electronic payment methods to improve response rates.

\section{Conclusions}

Our RCT showed that the proportion of smokers consenting to the 3-month follow-up and the retention rate generally increased with the incentive amount and offer of prepaid incentive. The combination of the prepaid and promised incentive (mixed incentive) was effective to increase the retention rate by $48 \%$. We recommend this mixed incentive scheme to increase the follow-up retention rate. More efficient methods of delivering incentive are needed to maximize its effects.

\section{Abbreviations}

ARR: Adjusted risk ratio; Cl: Confidence interval; Ecigs: E-cigarettes; HTP: Heated tobacco products; RCT: Randomized controlled trial; RR: Risk ratio; SPSS: Statistical Package for the Social Sciences; TCPS: Tobacco Control Policy-related Survey

\section{Acknowledgements}

We thank the telephone interviewers from the Public Opinion Programme of the University of Hong Kong for their work on data collection.

\section{Authors' contributions}

YTC: Conceptualization, Project Administration, Methodology, Supervision, Investigation, Software, Writing- Original draft preparation. XW: Data curation, Writing- Original draft preparation. MPW: Project Administration, Methodology, Supervision, Writing- Review \& Editing. SYH: Writing- Review \& Editing. CSK: Writing- Review \& Editing, Funding Acquisition. WYL: WritingReviewing and Editing, Funding Acquisition. THL: Conceptualization, WritingOriginal draft preparation. All authors read and approved the final manuscript.

\section{Funding}

This study was supported by the Hong Kong Council on Smoking and Health.

\section{Availability of data and materials}

The data that support the findings of this study are available from Hong Kong Council on Smoking and Health, but restrictions apply to the availability of these data, which were used under license for the current study, and so are not publicly available. Data are however available from the authors upon reasonable request and with permission of Hong Kong Council on Smoking and Health.

\section{Ethics approval and consent to participate}

This study was approved by the Institutional Review Board of the University of Hong Kong/Hospital Authority Hong Kong West Cluster (IRB reference number: UW 17-084). All trial participants provided an informed and verbal consent.

\section{Consent for publication}

Not applicable.

\section{Competing interests}

The funder was not involved in the collection, analysis and interpretation of the data, but two authors from the funder approved the submission of the manuscript

\section{Author details}

${ }^{1}$ School of Nursing, The University of Hong Kong, Hong Kong, China. ${ }^{2}$ School of Public Health, The University of Hong Kong, Hong Kong, China. ${ }^{3}$ The Hong Kong Council on Smoking and Health, Hong Kong, China. 
Received: 1 April 2019 Accepted: 26 June 2019

Published online: 04 July 2019

\section{References}

1. Kempf AM, Remington PL. New challenges for telephone survey research in the twenty-first century. Annu Rev Public Health. 2007;28(1):113-26.

2. Tuckel $P, O^{\prime} N$ eill $H$. The vanishing respondent in telephone surveys. J Advert Res. 2002;42(5):26-48.

3. Peytchev A, Carley-Baxter LR, Black MC. Multiple sources of nonobservation error in telephone surveys: coverage and nonresponse. Sociol Methods Res. 2011;40(1):138-68.

4. Galea S, Tracy M. Participation rates in epidemiologic studies. Ann Epidemiol. 2007:17(9):643-53.

5. Groves RM. Survey errors and survey costs. Hoboken, NJ, US: John Wiley \& Sons Inc 2004

6. Centers for Disease Control and Prevention. 2012-2013 National Adult Tobacco Survey: sample design and methodology summary. 2015.

7. Centers for Disease Control and Prevention. 2013-2014 National Adult Tobacco Survey: Sample Design and Methodology Report. 2016.

8. Thompson ME, Fong GT, Hammond D, et al. Methods of the international tobacco control (ITC) four country survey. Tob Control 2006;15 Suppl 3(Suppl 3):iii12-iii18.

9. Groves RM. Nonresponse rates and nonresponse bias in household surveys. Public Opin Q. 2006:70(5):646-75.

10. Studer J, Baggio S, Mohler-Kuo M, et al. Examining non-response bias in substance use research - are late respondents proxies for non-respondents? Drug Alcohol Depend. 2013;132(1):316-23.

11. Zhao J, Stockwell T, Macdonald S. Non-response bias in alcohol and drug population surveys. Drug and Alcohol Review. 2009;28(6):648-57.

12. Woodruff SI, Conway TL, Edwards CC. Increasing response rates to a smoking survey for US navy enlisted women. Evaluation \& the Health Professions. 2000; 23(2):172-81.

13. Keating NL, Zaslavsky AM, Goldstein J, et al. Randomized trial of $\$ 20$ versus $\$ 50$ incentives to increase physician survey response rates. Med Care. 2008; 46(8):878-81.

14. Halpern SD, Ubel PA, Berlin JA, et al. Randomized trial of 5 dollars versus 10 dollars monetary incentives, envelope size, and candy to increase physician response rates to mailed questionnaires. Med Care. 2002;40(9):834-9.

15. Leung GM, Johnston JM, Saing H, et al. Prepayment was superior to postpayment cash incentives in a randomized postal survey among physicians. J Clin Epidemiol. 2004;57(8):777-84.

16. Church $\mathrm{AH}$. Estimating the effects of incentives on mail response rates: a meta-analysis. Public Opin Q. 1993;57(1):62-79.

17. Pforr K, Blohm M, Blom AG, et al. Are incentive effects on response rates and nonresponse bias in large-scale, face-to-face surveys generalizable to Germany? Evidence from ten experiments. Public Opin Q. 2015;79(3):740-68.

18. Singer E, Van Hoewyk J, Maher MP. Experiments with incentives in telephone surveys. Public Opin Q. 2000;64(2):171-88.

19. Groves RM, Cialdini RB, Couper MP. Understanding the decision to participate in a survey. Public Opin Q. 1992;56(4):475-95.

20. Dillman DA, Smyth JD, Christian LM. Internet, mail, and mixed-mode surveys: the tailored design method, 3rd ed. Hoboken, NJ, US: John Wiley \& Sons Inc 2009.

21. O'Donoghue T, Rabin M. Doing it now or later. Am Econ Rev. 1999;89(1):103-24.

22. Berns GS, Laibson D, Loewenstein G. Intertemporal choice - toward an integrative framework. Trends Cogn Sci. 2007:11(11):482-8.

23. Hand DJ, Heil SH, Sigmon SC, et al. Improving medicaid health incentives programs: lessons from substance abuse treatment research. Prev Med. 2014;63:87-9.

24. Cheung DYT, Wang MP, Ho SY, et al. Report on tobacco control policyrelated survey 2017. Hong Kong SAR: Hong Kong Council on Smoking and Health; 2018.

25. Census and Statistics Department. Thematic household survey, Report No.64: Pattern of Smoking. Hong Kong SAR: Hong Kong SAR Government 2018.

26. Leung D, Chan S, Lam T. Prevalence and characteristics of hardcore smokers in Hong Kong. Hong Kong Med J. 2017;23(3 Supplement 2):4-9.

27. Leung DYP, Chan SSC, Chan V, et al. Hardcore smoking after comprehensive smoke-free legislation and health warnings on cigarette packets in Hong Kong. Public Health. 2016:132:50-6.

28. Cheung YTD, Wang MP, Ho SY, et al. Public support for electronic cigarette regulation in Hong Kong: a population-based cross-sectional study. Int J Environ Res Public Health. 2017;14(7):709.
29. Cheung YTD, Ho SY, Wang MP, et al. Pro-smoking responses and attitudes due to point-of-sale tobacco displays in never smokers: a cross-sectional study in Hong Kong. Tob Induc Dis 2018;16(July):32.

30. Olsen F, Abelsen B, Olsen JA. Improving response rate and quality of survey data with a scratch lottery ticket incentive. BMC Med Res Methodol. 2012; 12(1):52.

31. Guo Y, Kopec JA, Cibere J, et al. Population survey features and response rates: a randomized experiment. Am J Public Health. 2016;106(8):1422-6.

32. Gajic A, Cameron D, Hurley J. The cost-effectiveness of cash versus lottery incentives for a web-based, stated-preference community survey. Eur J Health Econ. 2012:13(6):789-99.

33. Wu C, Thompson ME, Fong GT, et al. Methods of the international tobacco control (ITC) China survey. Tob Control. 2010;19(Suppl 2):i1-5.

34. Young JM, O'Halloran A, McAulay C, et al. Unconditional and conditional incentives differentially improved general practitioners' participation in an online survey: randomized controlled trial. J Clin Epidemiol. 2015;68(6):693-7.

35. Ulrich CM, Danis M, Koziol D, et al. Does it pay to pay?: a randomized trial of prepaid financial incentives and lottery incentives in surveys of nonphysician healthcare professionals. Nurs Res. 2005;54(3):178-83.

36. Toepoel V. Effects of incentives in surveys. In: Gideon L, editor. Handbook of survey methodology for the social sciences. New York, NY: Springer; 2012. p. 209-23.

37. Kahn KL, Liu H, Adams JL, et al. Methodological challenges associated with patient responses to follow-up longitudinal surveys regarding quality of care. Health Serv Res. 2003;38(6p1):1579-98.

38. Collins RL, Ellickson PL, Hays RD, et al. Effects of incentive size and timing on response rates to a follow-up wave of a longitudinal mailed survey. Eval Rev. 2000;24(4):347-63.

39. Yu S, Alper HE, Nguyen A-M, et al. The effectiveness of a monetary incentive offer on survey response rates and response completeness in a longitudinal study. BMC Med Res Methodol. 2017;17(1):77.

40. Rose SW, Emery SL, Ennett S, et al. Public support for family smoking prevention and tobacco control act point-of-Sale provisions: results of a National Study. Am J Public Health. 2015;105(10):e60-7.

41. Smith KC, Siebel C, Pham L, et al. News on tobacco and public attitudes toward smokefree air policies in the United States. Health Policy. 2008;86(1):42-52.

42. Lykke $M$, Pisinger $C$, Glümer $C$. Ready for a goodbye to tobacco? assessment of support for endgame strategies on smoking among adults in a Danish regional health survey. Prev Med. 2016:83:5-10.

43. James KM, Ziegenfuss JY, Tilburt JC, et al. Getting physicians to respond: the impact of incentive type and timing on physician survey response rates. Health Serv Res. 2011:46(1p1):232-42.

\section{Publisher's Note}

Springer Nature remains neutral with regard to jurisdictional claims in published maps and institutional affiliations.
Ready to submit your research? Choose BMC and benefit from:

- fast, convenient online submission

- thorough peer review by experienced researchers in your field

- rapid publication on acceptance

- support for research data, including large and complex data types

- gold Open Access which fosters wider collaboration and increased citations

- maximum visibility for your research: over $100 \mathrm{M}$ website views per year

At BMC, research is always in progress.

Learn more biomedcentral.com/submissions 